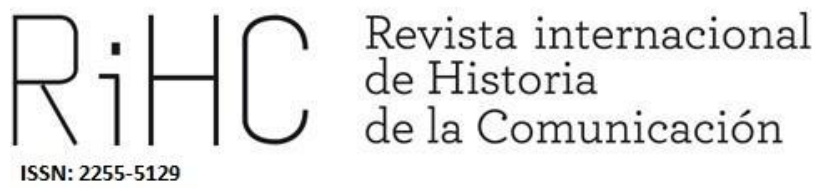

\title{
CINE ESPAÑOL EN LA ARGENTINA: LA EXPORTACIÓN DEL NACIONALISMO RURALISTA
}

Spanish film in Argentina: the export of ruralist nationalism

DOI: https://dx.doi.org/10.12795/RiHC.2020.i15.03

Recibido:4-9-2020

Aceptado: 5-11-2020

Publicado: 30-12-2020

Emeterio Diez Puertas

Universidad Camilo José Cela, España

edeiz@ucjc.edu

ORCID (iD) 0000-0002-2206-0480 
Resumen: El primer franquismo estableció una política cinematográfica basada en la autarquía, es decir, en un control estricto del comercio exterior tanto por razones económicas como ideológicas. Había que controlar la balanza de pagos y el ideario de los gobiernos extranjeros. Es así como, tras la Segunda Guerra Mundial, la Argentina se convierte en el principal socio del régimen. Sobre todo, porque la importación de cereales es vital para paliar el hambre. Es más, para solidificar esas relaciones, se estimula un intercambio cultural en el que el cine juega un relevante papel. En concreto, el objeto de estas páginas es estudiar el impacto comercial, artístico, moral y crítico del drama rural español exportado por España a la Argentina en el periodo de 1944 a 1947 y demostrar que este cine sirvió de difusión del ideario nacional ruralista entre los argentinos y, sobre todo, entre la colonia de emigrantes españoles, muchos de ellos procedentes del campo. Palabras clave: cine, franquismo, peronismo, drama rural, cronotopo.

\begin{abstract}
The first Francoism created a film policy based on autarky, that is, on strict control of foreign trade for both economic and ideological reasons. It was necessary to control the balance of payments and the ideology of foreign governments. This is how, after the Second World War, Argentina became the main partner of the regime. Above all because the importation of cereals is vital to alleviate hunger. Moreover, to solidify these relationships, a cultural exchange is encouraged in which the cinema plays an important role. Specifically, the purpose of these pages is to study the commercial, artistic, moral, and critical impact of the Spanish rural drama exported by Spain to Argentina in the period from 1944 to 1947. It is intended to show that this cinema served to disseminate the national ruralist ideology among Argentines and, above all, among the colony of Spanish emigrants, many of them from the countryside.
\end{abstract}

Keywords: Cinema, Francoism, Peronism, Rural Drama, Chronotope

\title{
Introducción y metodología
}

En 1972, David Manning White y Richard Averson titularon su libro sobre las relaciones entre el cine y la política estadounidense con la expresión El arma del celuloide. El título, sin duda, remite a la frase que Mussolini dice en 1922: «El cine es el arma más fuerte del Estado». Esta frase es, a su vez, una nueva formulación de la máxima de Lenin: «De todas las artes, el cine es para nosotros la más importante». Pues bien, si en España el franquismo da tanta importancia al cine es porque también entiende que las películas son sujeto agente: trasforman las costumbres, forman a los jóvenes, marcan la existencia de determinado tipo de familia o bien señalan, si un poder político sabe manejarlo, la marcha de los pueblos. Hasta uno de los intelectuales del régimen, Gumersindo Montes Agudo, utiliza una expresión parecida cuando en Primer Plano dice que el cine es un «arma de penetración política» (10 de junio de 1945).

En efecto, como en los regímenes totalitarios, el franquismo entiende que, por encima de la importancia del cine como industria y arte, está su alcance como instrumento 
político. Importan los premios artísticos, los puestos de trabajo o los beneficios de taquilla, pero más aún sus posibilidades como medio de comunicación de masas que forma y dirige al pueblo. Y como el cine nacional es incapaz de abastecer su propio mercado y hay un deseo de "proyectarse» en el exterior, no son los aranceles, la balanza comercial o los cupos la razón última para importar o exportar una película. Además de atenerse a la política económica autárquica del momento histórico que aquí vamos a estudiar, es preciso que el cine intercambiado tenga determinados rasgos ideológicos. El aparato del estado (Althusser, 1989) tiene que controlar el contenido del cine español que se exporta y del cine extranjero que se exhibe en todo el territorio. En un texto con un título tan significativo como «En la etapa decisiva», Antonio Fraguas Saavedra vuelve a vincular las palabras «cine» y «armas»:

Nos hallamos ante la etapa decisiva y están a la vista los males que en un momento dado pueden convertir al cine español en satélite de cualquier firmamento extraño [se refiere al cine norteamericano] [...] todo lo que niega o destroza la realidad de nuestro cine, convirtiéndolo en un monstruo sin cabeza, habrá de ser vencido en esta etapa decisiva del cine nacional.

Así lo piden todos los que han puesto en el cine al servicio de España sus recursos económicos, sus esfuerzos mejores y sus ilusiones más sanas. $Y$ así lo quieren quienes tienen encomendada la misión de no retroceder jamás en la lucha por dar a la Patria armas con que divulgar por la redondez de la tierra la inmensa y cristina verdad del pueblo más grande del mundo (cursiva nuestra, Primer Plano, 7-11945).

En concreto, desde al menos 1945, el régimen de Franco pone en marcha una campaña de propaganda bajo el lema "La verdad de España» cuyo objeto es hacer frente a la política de aislamiento internacional y a los intentos de derribar el régimen. Se trata de superar la crisis de legitimidad internacional divulgando, en el interior y en el exterior, lo sucedido en España en los últimos 15 años. Es decir, en la lucha por ganarse a la opinión pública nacional e internacional, franquistas y antifranquistas se adjudican la posesión de la "verdad» y crean toda una controversia sobre la naturaleza política del franquismo. La verdad de España, por ejemplo, es una publicación republicana editada en Santiago de Chile entre 1942 y 1948 bajo la dirección del novelista Diego Muñoz. Igualmente es un tema frecuente de la prensa de la época. Según Nuevo Correo, periódico profranquista editado en Buenos Aires, la verdad de España es esta:

Las grandes naciones democráticas y especialmente sus cancillerías, conocen bien el proceso turbulento y demagógico que desembocó en la guerra civil: saben que fue Rusia la que de acuerdo con sus parciales en España introdujo la revuelta y el caos para contar con una sucursal soviética en el occidente europeo, y que todos esos intentos fueron desbaratados y vencidos por el espíritu patriótico y abnegado del Movimiento Nacional. [...] El gobierno del general Franco salvó a España en la 
guerra, como la está salvando en la paz. Reina allí completa tranquilidad y veintiséis millones de españoles trabajan activa y diligentemente para colocar a su patria en la altura que por tantos y tan prelados títulos se merece (Nuevo Correo, 27-10-1945, pág. 1).

"La verdad de España» es, asimismo, el título del discurso que el ministro de Asuntos Exteriores y de Culto de la Argentina, Ruiz Guiñazú, pronuncia el 12 de octubre de 1942 con motivo del Día de la Raza (o al menos, ese es el título que la prensa franquista pone a su discurso). El ministro señala que España exploró con heroísmo el continente, llevó la civilización y difundió el credo católico. Reclama reforzar los lazos a fin de forjar un hispanoamericanismo activo, más allá de las palabras hueras, como son la firma en ese año de los acuerdos económicos y culturales entre la Argentina y España.

En tercer lugar, La verdad de España es una publicación del Instituto de Estadística con distintas ediciones, la primera de 1950, que mediante una serie de datos cuantitativos trata de demostrar el progreso de España, es decir, trata de desmentir con números las informaciones que en el mundo retratan a España como un país atrasado por culpa de la dictadura.

En el caso del cine, la campaña en favor de «la verdad de España» significa que el cine ha de mostrar al mundo que los españoles son una "raza» de personas católicas, valerosas, sacrificadas, fuertes, emprendedoras y alegres. Todas ellas son cualidades que hacen de los españoles hombres y mujeres que conviene tener como amigos y evitar como enemigos. Antonio Fraguas Saavedra, en este sentido, propone un cine español que muestre a España como una nación cristiana y guerrera, dispuesta a sacrificarse y luchar. Dice en un artículo titulado "¿Cómo puede ganarse el cine una nacionalidad?», publicado en Primer Plano el 1 de octubre de 1944, día del Caudillo:

Nos está fijada concretamente la tarea de crear el cine español y dotarlo de elementos suficientes para que pueda caminar con fuerzas propias. A todos, sin excepción, alcanza el objetivo de esta consigna [...] No logro explicarme las vacilaciones ante la meta de darle al cine español nacionalidad española. [...] La españolada es precisamente lo contrario de la personalidad española. [...] La personalidad española en el cine es cotizable siempre que se muestre tal como es. Pasiones, violencias, odios, amoríos, contrastes, colores, todo lo fuerte y crudo, cabe en el cine que quiera mostrar al mundo la España cristiana y guerrera dispuesta siempre a los grandes sacrificios y a las más violentas reacciones.

La mención reiterada que estamos haciendo de la revista Primer Plano tiene su justificación. Es una publicación oficial. A través de ella el Estado cumple una misión «inspiradora», esto es, le dice a la iniciativa privada qué cine debe rodar. Porque el franquismo, salvo su sector más fascista, nunca contempló nacionalizar o estatalizar esta industria. En efecto, el contenido que hace que una película sea «española», en realidad 
franquista, se deduce de las consignas que lanza esta revista, en especial, en el artículo de opinión que abre cada número hasta los años cincuenta. Son las «primeras de Primer Plano", un conjunto de textos escritos por los máximos responsables del cine del régimen: David Jato Miranda, delegado nacional de Propaganda, Patricio González Canales, secretario nacional de Propaganda, el mencionado Antonio Fraguas Saavedra, jefe nacional de Cine, o periodistas e intelectuales que escriben a su dictado. Por supuesto, los productores también deducen lo que el régimen desea de sus experiencias con la administración, desde la suerte del guion en la censura previa a la inspección del filme por la censura y la clasificación económica, pasando, además, por la concesión de créditos y premios sindicales o licencias de importación.

En concreto, el Estado debe asegurarse de que tanto el cine propio como el cine extranjero importado ayuden a la configuración de una conciencia nacional o "espíritu nacional». Bien es cierto que, la respuesta a la pregunta sobre qué cine rodar y qué cine exportar e importar es distinta dependiendo de la coyuntura. En estos momentos, se inicia la fase nacionalcatólica que, como su nombre indica, propone un cine basado en dos ideas o "verdades» fundamentales: el nacionalismo y el catolicismo. Ambas son la base de ese espíritu nacional, es decir, todo el cine es patriótico y apostólico y, al mismo tiempo, hay géneros específicos donde esos dos principios se despliegan, como el cine histórico o el cine religioso, los cuales, vistos desde fuera, resultan patrioteros y catequistas. En realidad, habría que hablar de "nacionalcatolicismo franquista», pues una política españolista y católica puede rastrearse antes y después del franquismo y antes y después de este momento concreto del franquismo. Es decir, con nacionalcatolicismo nos referimos a que, desde 1945, la Iglesia no solo controla la moralidad pública, sino que, además, los seglares se sitúan a la cabeza del aparato de propaganda del Estado. Sumado a que ya controlan las escuelas, los «propagandistas» tienen todo el poder para adoctrinar a los españoles.

Según el nacionalcatolicismo, los actos de los pueblos creyentes deben estar presididos por la fe. Hay que vencer el materialismo y seguir los principios de la ley divina, pues no son iguales las naciones que tienen moral de las que se dejan arrastrar por los vicios de la moderna vida urbana. Es más, el destino colectivo está subordinado a la benevolencia de Dios, pues este no solo juzga a los individuos sino también a las naciones y los pueblos. En concreto, según Patricio González Canales, secretario nacional de Propaganda, el espíritu nacional se alcanza rodando un cine al servicio de la unidad de la Patria y exhibiendo películas que fomente, sin mojigatería, sin ahorrar la crítica, el perfeccionamiento individual y social mediante la defensa de los principios y valores cristianos.

Este nacionalcatolicismo se concreta luego en decisiones que afectan a todas las esferas de la vida. En este sentido, el cine franquista muestra que, bajo el régimen, los conflictos de clase se resuelven con el corporativismo; la pobreza, con el socorro social; el orden 
público, con la policía; la rivalidad de partidos, con la democracia orgánica; las demandas de las nacionalidades, con el regionalismo; las trifulcas familiares, con el patriarcado; la sucesión del Estado, con la monarquía; las relaciones internacionales, con la hispanidad y el anticomunismo; la defensa nacional, con el ejército y el pueblo en armas.

Por ejemplo, hay una consigna para que el cine español presente con dignidad, y no solo con el recurso de la gracia burda, las costumbres regionales y la belleza de las tierras de España. El cine folclórico y, como veremos, el drama rural cumplen esta misión. Otra consigna pide que el cine exalte los hechos y las hazañas de los que con una actitud netamente hispana combatieron y dieron su vida por la grandeza de su Patria. Esta consigna explica el fenómeno del cine histórico. Hay consignas que, en cambio, restan posibilidades de desarrollo de un género. El policíaco español, por ejemplo, nunca debía presentar bandidos generosos en lucha contra la ley ni criminales que se salen con la suya. Tenía que contarse, más bien, desde policías que actúan con autoridad y disciplina. Lo mismo sucede con el drama social. El cronotopo del idilio laboral solo podía manifestarse en historias que exaltan el trabajo y la obligación de todos de cumplir con su esfuerzo a la elevación de España. Nada de protagonistas al borde de la miseria, de exaltación de vagos, de presentación de cochambre y mal vivir de las gentes. Eso eran temas del frentepopulismo.

Pues bien, el objeto de estas páginas es retratar esta política con el estudio de un caso: la exportación del drama rural a la Argentina, el país extranjero más importante para España en aquel momento (Delgado Gómez-Escalonilla, 1988; Figalo, 1992; Rein, 1995; González de Oleaga, 2001). Ello nos permitirá estudiar la mediación política que en la realidad (Berger \& Luckmann, 1986) y en las relaciones internacionales ejerce el cine trasnacional (Higbee \& Hwee Lim, 2010) y el interés del franquismo por dar visibilidad a unos temas, como el nacionalismo ruralista, que debía actuar sobre la compleja identidad de los emigrantes (García Sebastiani, 2020) y que nada tenía que ver con los temas que "los enemigos de España» proponen: falta de libertades, represión, hambruna, estraperlo... (Martí Gómez, 1995). En primer lugar, estableceremos la lista de títulos importados. Luego analizaremos el contenido ideológico del drama rural. Finalmente, estudiaremos la recepción de estas películas a través de la prensa argentina especializada (El Heraldo del Cinematografista e Imparcial Film). El marco temporal viene determinado por las peculiaridades del periodo comprendido entre 1944 y 1947. En 1943 tiene lugar un golpe de Estado en la Argentina mientras España vuelve a la neutralidad y en 1948 se firma el protocolo Franco-Perón y, como consecuencia de este, un acuerdo de intercambio de películas que transforma las relaciones cinematográficas. En fin, este trabajo forma parte de una línea de investigación que estudia las relaciones de España con la Argentina en el ámbito del cine y, más en concreto, es continuación de una tesis doctoral que se presentó en la Universidad Carlos III (Diez Puertas, 2016). 


\section{La exportación de películas a la Argentina}

La Argentina cuenta a finales de los años cuarenta con 16 millones de habitantes y unas 2.200 salas de cine. El $40 \%$ de ellas se concentran en la provincia de Buenos Aires y el otro 37\% está en tres provincias: Santa Fe, Córdoba y Mendoza. Es decir, se ubican en la franja central del país. Hay muy pocas salas al sur y al norte.

Tabla 1. Salas cinematográficas en la Argentina

\begin{tabular}{|l|l|l|l|}
\hline Zona & Salas & Zona & Salas \\
\hline Buenos Aires capital & 209 & P. de Santa Fe & 412 \\
\hline Gran Buenos Aires & 201 & P. de Santiago del Estero & 20 \\
\hline Provincia de Buenos Aires & 459 & P. de Tucumán & 47 \\
\hline P. de Catamarca & 7 & Gobernación de Chubut & 13 \\
\hline P. de Córdoba & 288 & G. de El Chaco & 53 \\
\hline P. de Corrientes & 33 & G. de Formosa & 13 \\
\hline P.de Entre Ríos & 86 & G. de La Pampa & 59 \\
\hline P. de Jujuy & 15 & G. de Misiones & 18 \\
\hline P. de Mendoza & 113 & G. de Neuquén & 23 \\
\hline P.de La Rioja & 5 & G. de Río Negro & 25 \\
\hline P. de Salta & 26 & G. de Santa Cruz & 11 \\
\hline P. San Juan & 28 & G. de Tierra del Fuego & 3 \\
\hline P. de San Luis & 17 & Total & 2184 \\
\hline
\end{tabular}

Fuente: Cuevas, 1950

Desde el punto de vista del exportador español, este mercado tiene cinco características a tener en cuenta. Dos son positivas: es un mercado aparentemente muy próspero porque casi todo el cine que llega a la Argentina termina viéndose en Uruguay y Paraguay, pues forman el área cinematográfica del Río de la Plata, y, además, hay un número muy elevado de emigrantes españoles. Sin embargo, hay tres inconvenientes: la competencia es muy grande por el volumen tan alto de títulos que se estrenan al año, el precio de las entradas es bajo y los costes de distribución son importantes o bien las empresas españolas exportadoras sufren la "orfebrería contable» de sus socios argentinos. Todo ello hace que muchos productores españoles se sorprendan cuando ven lo poco que ganan tras el estreno de sus películas, incluso con un filme de cierto éxito. Hasta se ofenden cuando ven por escrito las ofertas económicas que les hacen las compañías argentinas para comercializar su cine. Porque lo cierto es que, en este momento, el cine español se estrena en un número muy limitado de locales de la capital, como la Comedia, el Monumental y, sobre todo, el cine Gloria, el local que más frecuenta la emigración española. Aquí se estrena el $50 \%$ de las películas franquistas presentadas entre 1944 y 1947. Contar con este local es una suerte porque, terminada la guerra 
mundial, abundan las novedades y algunas de ellas tienen tanto éxito que se acumulan las películas sin sala donde estrenar.

Pero, una vez más, por encima de los intereses económicos están los políticos. Para el régimen de Franco la Argentina es un país prioritario. España necesita de sus cereales para paliar el hambre y, en consecuencia, es necesario que en el interior de la Argentina haya un clima favorable al régimen. Necesita comunicar la «verdad de España» para que estén de su lado los argentinos y la colonia española de emigrantes, sobre todo, porque el exilio republicano en el país trabaja en su contra (Ortuño Martínez, 2018). Incluido un número relevante de cineastas que han buscado refugio en el país, como Alejandro Casona o Rafael Alberti. Hay que recordar que en la Argentina hay una emigración muy fuerte de españoles, sobre todo, entre 1890 y 1914 y entre 1920 y 1929. Llegan alrededor de 130.000 emigrantes por año. Luego ese movimiento desciende a unos 43.000 entre 1930 y 1939. Finalmente, las buenas relaciones entre Franco y Perón y la buena imagen que el peronismo consigue en España (la Argentina se pone de moda y es sinónimo de prosperidad), animan a muchas personas a emigrar, pues, además, el peronismo adopta una postura de apertura a la emigración española. De este modo, entre 1945 y hasta 1960, emigran cada año una media de 62.000 españoles, sobre todo gallegos y, en un volumen inferior, canarios, catalanes y madrileños. La mayoría emigra por motivos económicos, pero también los hay que lo hacen para evitar la represión o para huir del asfixiante control moral, social y político (Farías, 2012). De hecho, el régimen teme que esta emigración dé fuerza a los exilados republicanos. Incluso para dejar España se pueden dar varias de estas motivaciones a la vez (Schwarzstein, 2001). En cualquier caso, entre los llegados antes de la guerra, el exilio republicano y la emigración de postguerra, hacia 1947 hay en la Argentina 750.000 españoles según los Anuarios Estadísticos de Argentina. Otras fuentes hablan de alrededor de 1 millón de españoles (Ortuño Martínez, 2010: 296). Todos ellos vienen a configurar una población más que suficiente para que el cine español tenga un público «natural» y pueda alcanzar una buena cuota del mercado cinematográfico argentino. Este público, por otra parte, explica los frecuentes cambios de títulos de las películas españolas en su estreno en la Argentina a fin de emplear palabras que dejen claro su origen. Odio se titulará De Galicia a Buenos Aires; Hogueras en la noche, En un pueblo de Aragón; Martingala, La copla andaluza; El camino del amor, España de mis amores; Orosia, Un corazón español; Escuadrilla, Sangre de España, etc. Por otra parte, muchos españoles en la Argentina han prosperado como actores, guionistas, músicos, directores, productores, distribuidores o exhibidores de películas y juegan un papel relevante en las relaciones cinematográficas entre España y la Argentina.

Es más, ambos países llevan más de diez años intentando regularizar el comercio cinematográfico mediante un acuerdo de intercambio de películas que, finalmente, se firma en 1948. En cualquier caso, desde 1939, el régimen da al cine argentino un trato preferente, es decir, la Argentina está entre los países escogidos por el franquismo para 
que su cine se pueda proyectar en las salas españolas. La autarquía impone un férreo control del comercio exterior y la censura un férreo control de los contenidos importados. Al mismo tiempo, el régimen solo permite que se exporten las películas que considera de "calidad», aunque la falta de película virgen por el boicot de Estados Unidos y la derrota de Alemania limita mucho la capacidad exportadora del cine franquista en estos momentos y el régimen tiene que ser menos exigente.

En concreto, entre 1944 y 1947, España estrena 40 películas en Buenos Aires. Es una media de 10 títulos por año. Ahora bien, parte del material es muy viejo, rodado en los años 30. Esta presencia de títulos antiguos, además de darse dos reestrenos, indica que en la capital argentina hay demanda de cine español, pero que esta se cubre con lo que se puede. Y decimos esto porque son filmes que se estrenan en el cine Gloria, la sala especializada en material español para emigrantes.

Las películas exportadas proceden básicamente de cuatro marcas y están ligadas a tres distribuidoras. La primera, Radium Films, es una empresa que actúa durante dos años comercializando viejas películas españolas de la etapa republicana. Con un catálogo así, poco podía durar. La segunda, Ballesteros, también es una empresa ligada a este periodo. Pero tiene su importancia porque es una empresa española vendiendo en la Argentina cine español, el de su marca y parte del de Suevia y Cifesa. Crear una sucursal siempre es más costoso e implica abrirse camino en un mercado desconocido, aunque los rendimientos son mayores si cosecha éxitos. Lo habitual es establecer una alianza con una empresa local. Esto es lo que sucede con la tercera distribuidora, Grandes Films, que será la marca en la Argentina de las películas de Emisora Films.

Para ponderar la repercusión del cine español exportado, hemos usado como fuente principal el Heraldo del Cinematografista, una revista especialmente pensada para los exhibidores. Con el propósito de ayudarles en la selección de títulos, el Heraldo clasificaba las películas según tres valores en una escala de 5 puntos por cada valor. Los tres valores eran el comercial, el artístico y el argumento. Según la puntuación total, la película obtenía la categoría de extraordinaria, especial, corriente y de complemento. Pues bien, las películas españolas de mayor impacto en Buenos Aires, según el Heraldo, son Goyescas, El escándalo, las dos extraordinarias, Inés de Castro, de categoría especial, y el drama rural Aquel viejo molino, con 8,5 puntos sobre 15 . Son las únicas que aprueban de un total de 40 estrenos. La película más comercial es El escándalo. Las más artística Goyescas y después, todas ellas con al menos 3 puntos sobre 5, El escándalo, Inés de Castro, Eugenia de Montijo y, de nuevo, Aquel viejo molino. Las que tienen mejor argumento son El escándalo, El destino se disculpa, España de mis amores/El camino del amor, también un drama rural, y Aquel viejo molino. En cambio, todo el cine de los años treinta, en varios casos estrenado con 10 años de diferencia respecto a su fecha de producción, está entre lo peor valorado. Es positivo que solo unos pocos títulos se 
estrenen fuera de temporada (diciembre-febrero), como El novio de Carmencita/Lluvia de millones, Setenta horas en el cielo y Sangre de España/Escuadrilla.

Tabla 2. Impacto de las películas de ficción españolas estrenadas en Buenos Aires (1944-1947)

\begin{tabular}{|c|c|c|c|c|c|}
\hline Título & Año & Estreno & Controlador & $\begin{array}{l}\text { Impacto } \\
\text { sobre } 15\end{array}$ & Categoría \\
\hline Goyescas & 1942 & $23-6-1944$ & $\begin{array}{l}\text { Inconveniente } \\
\text { para niños }\end{array}$ & 10,5 & Extraordinaria \\
\hline El escándalo & 1943 & $18-8-1944$ & $\begin{array}{l}\text { Sin } \\
\text { restricciones }\end{array}$ & 9,5 & Extraordinaria \\
\hline Inés de Castro & 1944 & $4-4-1946$ & $\begin{array}{l}\text { Sin } \\
\text { restricciones }\end{array}$ & 8,5 & Especial \\
\hline Aquel viejo molino & 1946 & $22-5-1947$ & $\begin{array}{l}\text { Sin } \\
\text { restricciones }\end{array}$ & 8,5 & Corriente \\
\hline $\begin{array}{l}\text { España de mis amores } \\
\text { / El camino del amor }\end{array}$ & 1943 & $30-5-1946$ & $\begin{array}{l}\text { Sin } \\
\text { restricciones }\end{array}$ & 8 & Corriente \\
\hline Te quiero para mí & 1944 & 29-6-1945 & $\begin{array}{l}\text { Sin } \\
\text { restricciones }\end{array}$ & 7 & Corriente \\
\hline El destino se disculpa & 1945 & 1-11-1945 & $\begin{array}{l}\text { Sin } \\
\text { restricciones }\end{array}$ & 7 & Corriente \\
\hline $\begin{array}{l}\text { Los amores de } \\
\text { Espronceda / } \\
\text { Espronceda }\end{array}$ & 1945 & $15-3-1946$ & $\begin{array}{l}\text { Sin } \\
\text { restricciones }\end{array}$ & 7 & Corriente \\
\hline Eugenia de Montijo & 1944 & $9-8-1946$ & $\begin{array}{l}\text { Sin } \\
\text { restricciones }\end{array}$ & 7 & Corriente \\
\hline $\begin{array}{l}\text { El nacimiento de } \\
\text { Salomé }\end{array}$ & 1940 & $6-6-1944$ & $\begin{array}{l}\text { Sin } \\
\text { restricciones }\end{array}$ & 6 & Corriente \\
\hline $\begin{array}{l}\text { En un pueblo de } \\
\text { Aragón / Hogueras en } \\
\text { la noche }\end{array}$ & 1936 & $22-6-1944$ & $\begin{array}{l}\text { Inconveniente } \\
\text { para niños }\end{array}$ & 6 & Corriente \\
\hline Un marido a precio fijo & 1942 & $13-9-1945$ & $\begin{array}{l}\text { Sin } \\
\text { restricciones }\end{array}$ & 6 & Corriente \\
\hline Dora, la espía & 1943 & $28-8-1946$ & $\begin{array}{l}\text { Sin } \\
\text { restricciones }\end{array}$ & 6 & Corriente \\
\hline $\begin{array}{l}\text { Un corazón español / } \\
\text { Orosia }\end{array}$ & 1943 & $24-10-1946$ & $\begin{array}{l}\text { Sin } \\
\text { restricciones }\end{array}$ & 6 & Corriente \\
\hline La patria chica & 1943 & $25-9-1947$ & $\begin{array}{l}\text { Sin } \\
\text { restricciones }\end{array}$ & 6 & Corriente \\
\hline $\begin{array}{l}\text { Garbancito de La } \\
\text { Mancha }\end{array}$ & 1945 & 20-11-1947 & $\begin{array}{l}\text { Sin } \\
\text { restricciones }\end{array}$ & 6 & Corriente \\
\hline Forja de almas & 1943 & $2-3-1944$ & $\begin{array}{l}\text { Sin } \\
\text { restricciones }\end{array}$ & 5,5 & Corriente \\
\hline Campeones & 1943 & 28-8-1945 & $\begin{array}{l}\text { Sin } \\
\text { restricciones }\end{array}$ & 5,5 & Corriente \\
\hline Doce lunas de miel & 1943 & $13-9-1945$ & $\begin{array}{l}\text { Sin } \\
\text { restricciones }\end{array}$ & 5,5 & Corriente \\
\hline Castañuelas & 1945 & $10-10-1945$ & $\begin{array}{l}\text { Sin } \\
\text { restricciones }\end{array}$ & 5,5 & Corriente \\
\hline
\end{tabular}




\begin{tabular}{|c|c|c|c|c|c|}
\hline La rueda de la vida & 1942 & $30-8-1945$ & $\begin{array}{l}\text { Sin } \\
\text { restricciones }\end{array}$ & 5 & Complemento \\
\hline $\begin{array}{l}\text { El novio de Carmencita } \\
\text { / Lluvia de millones }\end{array}$ & 1940 & 20-2-1945 & $\begin{array}{l}\text { Sin } \\
\text { restricciones }\end{array}$ & 5 & Complemento \\
\hline Macarena & 1944 & $27-9-1946$ & $\begin{array}{l}\text { Sin } \\
\text { restricciones }\end{array}$ & 5 & Corriente \\
\hline Turbante blanco & 1945 & 8-11-1946 & $\begin{array}{l}\text { Sin } \\
\text { restricciones }\end{array}$ & 5 & Corriente \\
\hline $\begin{array}{l}\text { La copla andaluza / } \\
\text { Martingala }\end{array}$ & 1940 & 26-7-1945 & $\begin{array}{l}\text { Sin } \\
\text { restricciones }\end{array}$ & 4,5 & Corriente \\
\hline Molinos de viento & 1937 & 29-3-1945 & $\begin{array}{l}\text { Sin } \\
\text { restricciones }\end{array}$ & 4,5 & Complemento \\
\hline Canelita en rama & 1943 & $14-3-1946$ & $\begin{array}{l}\text { Sin } \\
\text { restricciones }\end{array}$ & 4,5 & Complemento \\
\hline Rosario, la cortijera & 1935 & Abril 1944 & $\begin{array}{l}\text { Sin } \\
\text { restricciones }\end{array}$ & 4 & Complemento \\
\hline $\begin{array}{l}\text { La boda de Quinita } \\
\text { Flores }\end{array}$ & 1943 & $10-10-1945$ & $\begin{array}{l}\text { Sin } \\
\text { restricciones }\end{array}$ & 4 & Complemento \\
\hline $\begin{array}{l}\text { Sesenta horas en el } \\
\text { cielo }\end{array}$ & 1935 & $28-2-1946$ & $\begin{array}{l}\text { Sin } \\
\text { restricciones }\end{array}$ & 4 & Complemento \\
\hline $\begin{array}{l}\text { De Galicia a Buenos } \\
\text { Aires/Odio }\end{array}$ & 1933 & $9-11-1944$ & $\begin{array}{l}\text { Inconveniente } \\
\text { para niños }\end{array}$ & 3,5 & Corriente \\
\hline $\begin{array}{l}\text { Las cinco advertencias } \\
\text { de Satanás }\end{array}$ & 1937 & $17-5-1945$ & $\begin{array}{l}\text { Inconveniente } \\
\text { para niños }\end{array}$ & 3 & Complemento \\
\hline $\begin{array}{l}\text { Una sombra en la } \\
\text { ventana }\end{array}$ & 1944 & 6-9-1946 & $\begin{array}{l}\text { No apta } \\
\text { menores de } \\
14 ; \\
\text { inconveniente } \\
\text { menores de } 18\end{array}$ & & Complemento \\
\hline Empezó en boda & 1944 & 23-8-1946 & $\begin{array}{l}\text { Sin } \\
\text { restricciones }\end{array}$ & & Complemento \\
\hline Idilio en Mallorca & 1942 & $24-10-1946$ & $\begin{array}{l}\text { Sin } \\
\text { restricciones }\end{array}$ & & Complemento \\
\hline La aldea maldita & 1942 & 21-11-1946 & $\begin{array}{l}\text { Sin } \\
\text { restricciones }\end{array}$ & & Complemento \\
\hline $\begin{array}{l}\text { Sangre de España / } \\
\text { Escuadrilla }\end{array}$ & 1941 & $2-1-1947$ & $\begin{array}{l}\text { Sin } \\
\text { restricciones }\end{array}$ & & Complemento \\
\hline Hombres sin honor & 1944 & $23-5-1947$ & $\begin{array}{l}\text { Inconveniente } \\
\text { menores } 14 \\
\text { años }\end{array}$ & & Complemento \\
\hline $\begin{array}{l}\text { Tormento en el alma / } \\
\text { El obstáculo }\end{array}$ & 1945 & $28-8-1947$ & $\begin{array}{l}\text { Sin } \\
\text { restricciones }\end{array}$ & & Complemento \\
\hline $\begin{array}{l}\text { Celos, amor y toros / El } \\
\text { centauro }\end{array}$ & 1946 & 20-11-1947 & $\begin{array}{l}\text { Sin } \\
\text { restricciones }\end{array}$ & & Complemento \\
\hline
\end{tabular}

Fuente: El Heraldo del Cinematografista

Lo que caracteriza a estos éxitos es que, para contar la verdad de España, el cine franquista recurre a tres fuentes, a menudo combinadas entre sí: la historia, la literatura y lo popular o folklórico. En realidad, en esto, el cine español es poco original, pues otros 
países de ideología nacionalista han usado o usan una estrategia similar. Años después Vicente Casanova explicará así la línea de producción emprendida en este momento:

La cinematografía hispana [española] consciente de la grave responsabilidad que sobre ella pesa, en su contribución para mostrar el espíritu de su pueblo, y los valores de su literatura y arte, como fiel reflejo de su personalidad en el mundo, huye de los temas ajenos a la idiosincrasia española, y se encauza hacia su historia, o hacia el manantial inagotable de su acervo popular, o al ingenio de sus escritores más famosos, por estar más de acuerdo con la raigambre de nuestro temperamento y nuestro sentido de la vida, que es como dar a la pantalla hispana, el sello de su propia y original personalidad (SET, abril mayo, 1950: 19)

Locura de amor, Don Quijote de La Mancha y La Lola se va a los puertos son los filmes que ejemplifican esa línea editorial por parte de Cifesa. Los tres títulos llegarán más tarde a la Argentina. En estos momentos, esas fuentes están representadas por tres de los éxitos mencionados: Inés de Castro, El escándalo y Goyescas.

Por otro lado, un número muy significativo de los éxitos (o de los estrenos) son películas de Interés Nacional, esto es, pertenecen al cine que, desde 1944, el régimen alienta específicamente para contar la verdad de España. En concreto, de las 43 películas declaradas de Interés Nacional entre 1944 y 1951, el 63\% se estrenan en Buenos Aires antes de 1955 y sabemos que algunas otras, como Bambú, Alba de América o El santuario no se rinde, se intentaron exportar sin éxito.

La paradoja es que, del conjunto de filmes españoles estrenados entre 1944 y 1947 en Buenos Aires, el actor que más películas protagoniza, cinco títulos, es el italiano Adriano Rimoldi. Rimoldi había sido uno de los galanes del cine fascista y había participado en las coproducciones promovidas por la entente entre Franco y Mussolini. En 1943, sin embargo, se produce el desembarco de los aliados y la proclamación de la República de Salo, por lo que se traslada a Barcelona para trabajar en Emisora Films. Es esta empresa la que lleva cuatro de sus películas a la Argentina. Pero el Heraldo lo tacha de frío galán y actor discreto o solo correcto, aunque progresa mucho, dice la revista, en Aquel viejo molino.

En cuanto a la valoración moral y por edades, dato que procede de la comisión de censura de la capital, la mayoría de las películas pasan sin restricciones. Solo un título es inconveniente para menores de 18 años, Una sombra en la ventana, y otro no apto para menores de 14, Hombres sin honor. Ambas tienen en común que son producciones de Emisora Films y thrillers sobre el mundo del crimen, una línea de producción de la casa barcelonesa que no se considera acta para todos los públicos.

Analizadas por géneros, en líneas generales, el tipo de filmes exportados se corresponde con los itinerarios genéricos del cine español en aquel momento. En concreto, las películas españolas más demandadas en la Argentina siguen siendo las adscritas a la 
comedia, sobre todo, la comedia sentimental, el cine musical-folklórico y el drama. La novedad del periodo es la exportación del drama biográfico o histórico, más algún caso de cine policíaco y de animación. También es relevante que el drama se desarrolle como drama rural.

\section{El cronotopo del idilio rural}

En cuanto al drama rural, si la comedia franquista es el género urbano por excelencia, el drama es el terreno del campo, si bien la crítica argentina alaba este tipo de filmes por su carácter etnográfico (costumbres, bailes, canciones, labores, paisajes...) más que por sus tramas, demasiado melodramáticas en ocasiones. También podríamos decir que, si la comedia expresa los deseos de la burguesía y la clase media urbana conservadora, el drama rural hace protagonista al campesino, un grupo social que estuvo del lado de Franco y fue compensado, por ejemplo, con el control de los precios agrícolas. Es decir, el régimen, en estos momentos sin apenas voces disidentes, refleja en la pantalla el mundo y los deseos de las clases y los grupos sociales que son parte y sostienen ese régimen. Dice Blanco Rodríguez:

Los valores del franquismo, al menos los de sus primeros tiempos, son fundamentalmente rurales. [...] La tierra, la tierra de Castilla, se convierte en depositaria de valores eternos y como tal en valor político. Abundan los elogios del régimen al mundo campesino frente al marcado cariz revolucionario de "los trabajadores mejor pagados de las ciudades», en palabras de Franco. [...] De hecho los objetivos de la política agraria del nuevo régimen en sus primeros años van en esa dirección de ampliar y consolidar el grupo social de los pequeños y medianos campesinos que desde la óptica franquista eran conservadores «por naturaleza, por tradición». Ellos darían estabilidad al nuevo estado (1998: 368).

El drama rural podemos relacionarlo con lo que Bajtín (1989) llama el cronotopo rural o laboral agrícola. Esta forma de ficción muestra la vinculación secular de generaciones a un determinado espacio. Sus protagonistas son campesinos, pastores, maestros... que viven en las fronteras espaciales marcadas por la tierra (los ríos, el campo, las montañas...), en fronteras temporales marcadas por el sol y las costumbres y en las fronteras ideológicas de un código moral muy estricto y de un desmedido orgullo. «Más vale ser amo pobre que criado rico», se dice en La aldea maldita en alusión al proletario que prospera trabajando en la fábrica. También aparecen personas que han ido a curarse con el contacto con la naturaleza y con el trato con gente simple o que regresan después de años de ausencia, tras vivir en la ciudad o en el extranjero. 
Bajtín sostienen que este cronotopo se manifiesta, especialmente, en la novela regional, en la que se dan, al mismo tiempo, el idilio amoroso y el familiar. En efecto, la novela regionalista es un relato situado en un entorno rural o provinciano sobre unos seres pegados a una tierra que es lo mejor y lo peor: la tierra es la que permite la subsistencia y la que te quita la vida, la que dicta las sabias costumbres y marca las duras labores, la que brinda belleza e infunde temor. El relato está lleno de lugares pintorescos, de tipos locales, de escenas costumbristas que nos dan cuenta de las leyes, bailes, comidas, vestimentas... singulares del lugar. Sus conflictos principales son con el medio (la sequía, la tormenta, el granizo, las plagas..), con otros personajes (las disputas amorosas, los resabios congénitos entre familias, las rivalidades políticas...) e internos derivados del estricto código de honor campesino.

José María de Pereda, cultivador de la novela regional, define este género así:

aquella cuyo asunto se desenvuelve en una comarca o lugar que tiene vida, caracteres y color propios y distintos, los cuales les entran en la obra como parte principalísima de ella [...] no cabe dentro de ella la novela urbana [...] La novela a que yo me refiero aquí, tiene más puntos de contacto con la naturaleza que con la sociedad; con lo perdurable, que con lo efímero y pasajero (De Pereda, 1897: 10).

El escritor asegura que este tipo de relato nace de un sentimiento que llama regionalismo, pasión acerca de la cual se tienen equivocados conceptos, como que conduce al desmembramiento de la patria grande, cuando es amor al terruño natal, a sus leyes y costumbres, a su aire, a su luz, sus fiestas, su música... El regionalismo es "saludable, elevado y patriótico» (De Pereda, 1897: 11) y está amenazado por los modernizadores, que consideran que el progreso es uniformizar, y también por el extranjerismo, la moda de copiar lo de fuera. Franco en sus discursos, precisamente, achacará la decadencia de la patria a una modernidad que desprecia las tradiciones y a una imitación extranjerizante que acosa las costumbres nacionales.

En el ámbito del teatro, el cronotopo del campo se manifiesta en el drama rural. Como la novela regional, es producto de los cambios que trae la revolución industrial: trabajo fabril, aparición del proletariado, emigración del campo, masificación de las ciudades, etc. En España este género es muy popular desde finales del siglo XIX y hasta la guerra civil. Es más, muchas de estas obras se llevan a la pantalla como La Dolores (1892), de José Feliú y Codina, La malquerida (1913), de Jacinto Benavente, y Nobleza Baturra (1924), de Joaquín Dicenta. Es decir, tanto el cine mudo como el cine sonoro llevan a las pantallas la novela regional y el drama rural. Lo que hace el franquismo es reivindicarlo, reforzarlo y adaptarlo a sus intereses. Como puede observase por los títulos, en el drama rural, el conflicto principal solo en contadas ocasiones se plantea con la tierra, que sería lo más específico, quizás por la dificultad de ponerlo en escena. Lo habitual es que el drama se desarrolle sobre el idilio amoroso sexual y el familiar, siendo el medio rural el contexto y el causante de que esos idilios se desarrollen de una forma más dramática, 
más primitiva. Es más, lo amoroso sexual coloca a la mujer y su honra en el centro de la trama, al punto de que podríamos decir que el drama rural es una manifestación del drama de honor, muy presente en el cine español visto en la Argentina (Diez Puertas, 2017: 226). El honor castellano y las tierras es lo que el padre deja al hijo, se dice en La aldea maldita.

González Requena, en este sentido, sostiene que lo que caracteriza esta forma de drama es la existencia de: 1) un código moral muy rígido que contiene un tabú sexual, 2) la transgresión real o aparente de ese tabú, y 3) su publicidad, lo que hace que todo el cuerpo social deba pronunciarse y el odio se instale entre los personajes (González Requena, 1988: 17).

\section{Los estrenos}

Precisamente, uno de los primeros títulos estrenados en la Argentina tiene por título Odio, filme de Richard Harlan rodado antes de la guerra. En la Argentina se estrena en noviembre de 1944 y se titula De Galicia a Buenos Aires para subrayar la importancia del espacio dramático, pues, en efecto, trata de unos personajes que terminan emigrando a la Argentina, aunque nunca se ve un plano de este país. En concreto, cuenta la historia de una mujer que fue seducida y tiene un hijo fruto de ese hombre que odia. Mucho tiempo después, el joven tiene que elegir entre irse con su novia a la Argentina o quedarse con su madre, que es víctima de un usurero. El joven se queda y, al ver el amor del hijo, la madre vende la casa y emigra también. La película se basa en una novela de Wenceslao Fernández Flórez «en la que se describe la dura existencia de los habitantes de un típico pueblo de Galicia, víctimas del ambiente y de su propia indolencia y que además han caído en las garras de un usurero», dice la sinopsis del Heraldo. Esta temática tan próxima al público español en la Argentina explica que la película se estrene más de diez años después de su realización. Imparcial Film dice que la realización es anticuada y el tono excesivamente sombrío y melodramático. El Heraldo coincide: tiene interés el tipismo, pero la técnica es pésima, el tema, folletinesco y el diálogo, teatral.

También de época republicana es Hogueras en la noche, de Arturo Porchet, titulada en la Argentina En un pueblo de Aragón. Se estrena en junio de 1944. La acción se desarrolla en un pueblo minero. Un joven del lugar huye a América para evitar tener que casarse con una joven a la que ha dado palabra de matrimonio. Cuando vuelve años después, la encuentra casada con su hermano, pero intenta conquistarla. Finalmente, el seductor muere en un accidente de tren. Por encima de esta trama folletinesca, Imparcial Film considera que su atractivo está en los cuadros folclóricos, bailes y canciones regionales. 
El camino del amor, dirigida por José María Castellvi, se estrena en la Argentina en mayo de 1946 y se titula España de mis amores en un intento de subrayar la parte que la película tiene de estampas costumbristas castellanas: bailes, música, trabajos agrícolas, feria en el pueblo, etc. La trama se centra en el idilio familiar. Es la historia de Pedro Calvo (Jacinto Quincoces), un rico campesino. Su mujer muere y él queda a cargo de su hijo Andrés y de su hija Teresita, todavía unos niños. Pedro decide tomar una criada, Tomasa, para que lleve la casa y cuide de los hijos, pero está criada le roba, maltrata a los niños y ambiciona casarse con él para quedarse con su patrimonio. Un día en el mercado una mujer, Dolores (Alicia Romay), le ayuda comprar ropa para los niños y entre ambos se establece una relación de amistad que se convierte en el rumor del pueblo. Dolores es honrada, hacendosa y guapa. El médico y el maestro aconsejan a Pedro que se case con Dolores, pues los niños necesitan «la mano de una madre». Pero el hijo rechaza a Dolores. La «odia». Celebrado el matrimonio, Andrés intenta hacer creer a su padre que Dolores es mala, pero su trampa falla y se escapa de casa. Todos salen a buscarlo. Dolores lo encuentra en la orilla del río, justo cuando tropieza y cae al agua. Dolores se arroja al río y lo salva. En casa, el médico consigue recuperar al niño y éste pide perdón a Dolores, a la que llama «madre». Entonces el médico dice: "Solo Dios conoce el camino del amor». Aunque el Heraldo la clasifica como corriente, la puntúa con un 8 sobre 15 y resalta muchas cualidades: el argumento humano y simpático, la buena música del maestro Jacinto Guerrero y los ambientes naturales. En efecto, la película, que está salpicada de temas musicales cantados por los protagonistas, refleja muy bien el ambiente de un pueblo rural: las tareas del campo, el vestuario de las gentes y costumbres etnográficas como la ceremonia de boda.

El centauro, presentada en noviembre de 1947, se titula en la Argentina Celos, amor y toros porque trata de la rivalidad entre dos ganaderos de reses bravas mientras dos jóvenes de ambas familias se enamoran. En otras palabras, una versión de Romeo y Julieta que el Heraldo solo considera de interés para los públicos españoles por la abundancia de exteriores, las escenas de corridas de toros y las canciones.

\subsection{La mujer rural como ideal patriótico: Orosia (1944)}

Entre los cultivadores más importantes del drama rural está Florián Rey (García Carrión, 2007), uno de los directores españoles con mayor presencia en las pantallas de la Argentina. El 1942 había estrenado en España La aldea maldita, nueva versión de su película de 1929, y al año siguiente había rodado Orosia. Florián Rey considera que el cine folclórico y el drama rural son formas de género netamente «españolas». En 1944 dice en Primer Plano: 
si queremos mantener nuestras películas en el mercado extranjero no hay otra receta posible que volver a un tipo de películas de ambiente español, sin miedo a utilizar el costumbrismo y el folclore. Ya se vio el éxito de Carmen la de Triana... ahora se sufre el fracaso de esta nueva tendencia de hacer películas frívolas de corte norteamericano [se refiere a la copia de las comedias sentimentales de Hollywood]. Nosotros no somos norteamericanos, ni contamos con todos esos recursos que posee la cinematografía yanqui. Convencido de esto y de que un español no puede hacer españoladas aunque se lo proponga, estoy decidido por la película de asunto genuinamente español (10 de septiembre de 1944).

Las dos películas mencionadas llegan a la Argentina a finales de 1946. La primera en estrenarse es Orosia. Lo hace con el título Un corazón español. La acción se sitúa en 1909 en un pueblo del Alto Aragón. Un viejo pastor cuida el ganado de su señora Orosia. Se cruza con él un hombre pendenciero, Venancio (José Sepúlveda), que ha pasado la frontera con Francia para regresar al pueblo. En casa de Orosia (Blanca de Silos), se prepara su ajuar. Al mismo tiempo, los padres de su novio llegan para pedir su mano. Del acuerdo matrimonial se ocupa su padrino, pues Orosia es huérfana pero rica: tierras, ganado y muchas piezas de oro. También los padres de su novio, Eloy, son ricos. Pero Venancio conspira contra esa boda. Aprovechando que las negociaciones económicas para el matrimonio quedan en suspenso, hace correr el rumor de que Orosia y Eloy han roto y alienta a Joselón (José Nieto), un antiguo pretendiente, para que la corteje. Este acude al balcón de Orosia con una ronda a cantarla coplas. Pero se produce una pelea con Eloy y este cae muerto. Venancio huye a Francia por las montañas y Joselón es llevado a juicio, siendo declarado inocente por falta de pruebas. Orosia, obsesionada con saber quién es el asesino, manda a los criados que salgan en busca de Venancio, pero le encuentran muerto en las montañas. Tiempo después, Orosia perdona a Joselón y comienza una relación con él que todos en el pueblo ven como un escándalo. Ella manda cambiar la inicial de Eloy por la de José en su ajuar y se casa con él. Pero todo es una trampa. La noche de bodas Orosia logra sacar a Joselón que él mato a Eloy. Entonces Orosia, llena de «odio», llama a gritos a los criados y le apresan. Tiempo después, Orosia muere y se une con Eloy compartiendo la misma tumba. Al Heraldo del Cinematografista le gusta la trama, la fotografía, la interpretación de la protagonista y los hermosos exteriores fotografiados por Heinrich Gärtner. Se refiere, en especial, a la misa de los pastores que se celebra en la montaña, la cual tiene casi un carácter de documental. 


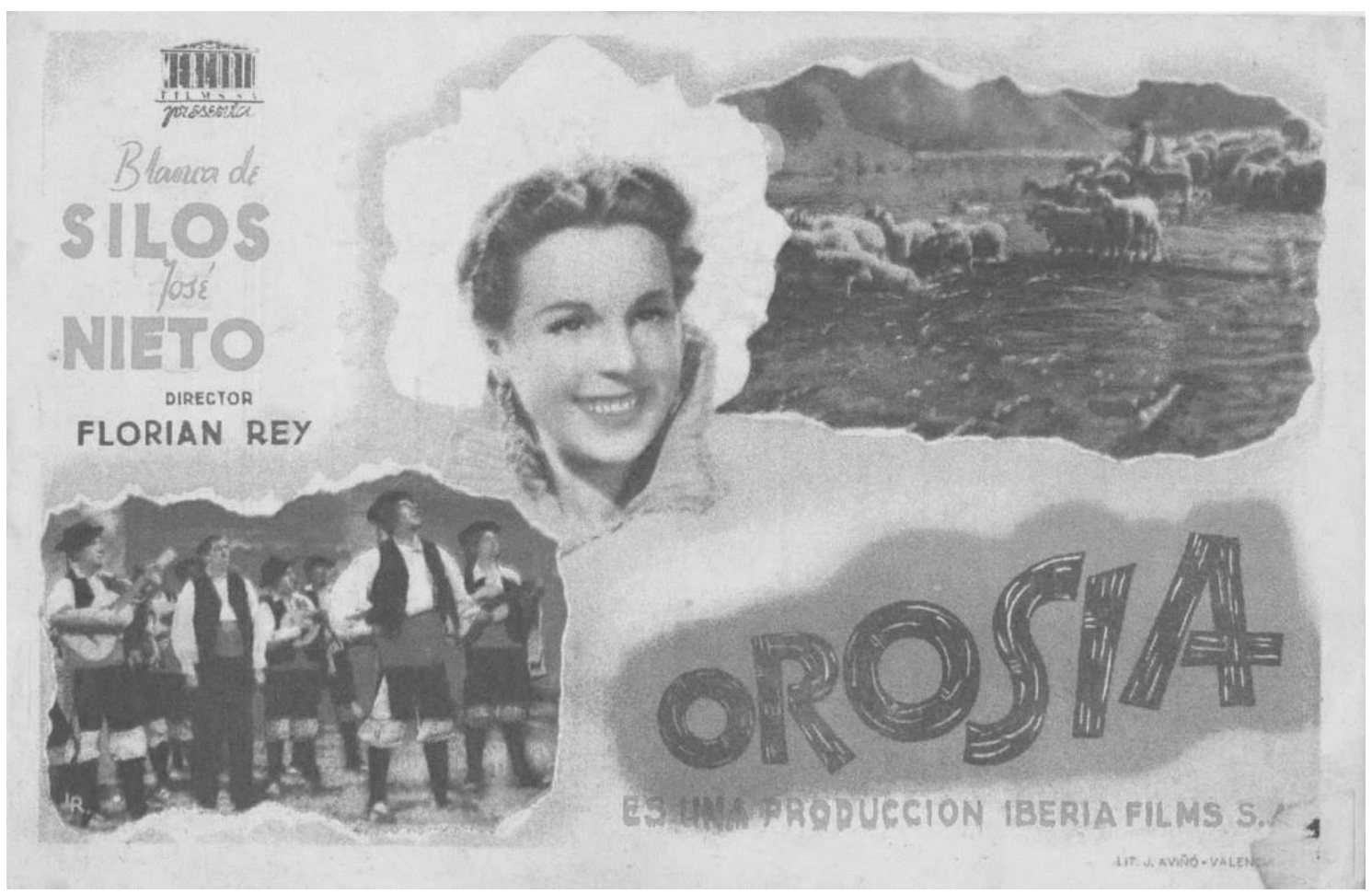

Cartel de la película Orosia con imagen de la protagonista, de una rondalla aragonesa y paisajes del Pirineo. Fuente: Filmoteca Española.

Orosia, por otra parte, tiene su importancia porque ejemplifica muy bien el protagonismo que en el drama rural tiene la mujer. La apelación al mundo rural por parte de la novela y el teatro no obedece solo a una corriente estética. Hay detrás un pensamiento político: un discurso nacional ruralista que exalta las virtudes campesinas y el medio rural. Antes de la guerra este pensamiento se encontraba en el catolicismo social, el ultranacionalismo y el fascismo. El franquismo lo asume y lo defiende. Pues bien, el nacional ruralismo convierte a la mujer en símbolo de los valores del agrarismo y el tradicionalismo y, al mismo tiempo, le confía la defensa de esos valores frente al avance de la izquierda marxista y anarquista, el laicismo, el ateísmo, el materialismo individualista o el internacionalismo antipatriótico. Es decir, las mujeres rurales con su austeridad, fortaleza, sencillez, fe cristiana, su honra y su arraigo a la tierra se convierten en un nuevo ideal patriótico.

\subsection{El pecado del orgullo: La aldea maldita (1942)}

En cuanto a La aldea maldita, su premisa es la propia del cronotopo del trabajo agrícola: cuando la ciudad abandona a los campesinos a las inclemencias de la naturaleza, la nación se desangra en forma de pueblos arruinados, éxodo y miseria. En concreto, la acción se sitúa en una aldea de Salamanca en 1900. Es casi el mismo tiempo diegético de Orosia y un cambio relevante respecto a la versión muda, que se situaba en 1929, es decir, en la fecha de rodaje del filme. No está claro si esta distancia temporal es para 
hacer el filme más etnográfico o para evitar que cualquier situación problemática se vea como una crítica del campesinado o del régimen. La trama es la siguiente. Un rico labrador castellano, Juan (Julio Rey), se ve obligado a ir a trabajar fuera tras varios años de malas cosechas. Pero su mujer, Acacias (Florencia Bécquer), en lugar de esperarle, se va a Salamanca, donde comienza una carrera de mujer de la noche.

Méndez-Leite en España dice que la realización es buena y tiene belleza plástica y una ambición artística loable, pero cae a veces en el efectismo teatral y la interpretación es mejorable (1965, Tomo I: 432). En la Argentina se estrena el noviembre de 1946. El Heraldo escribe que es una película de complemento. El argumento no tiene interés y es confuso, aunque sus estampas costumbristas están muy bien, con una excelente fotografía y hermosos exteriores (27 de noviembre de 1946: 206). En efecto, el filme está lleno de eso que hemos llamado elementos etnográficos propios del trabajo agrícola: el campo destrozado por la piedra, los bueyes arando la tierra, la recogida de la cosecha, la trilla y hasta el "día del patrón», la fiesta en la que los amos de la casa sirven a los criados, aparente símbolo de igualdad de clases. Imparcial Film, que a menudo está cerca de la paráfrasis publicitaria, escribe que es una buena película, un poema cinematográfico sobre el amor a la tierra y la honra de la mujer por encima de la misma muerte (25 de noviembre de 1946: 11).

Por otro lado, La aldea maldita vuelve a insistir en el ideal de mujer rural, solo que a través de su cara negativa. Acacias representa un modelo de mujer totalmente opuesto a Orosia y a lo que esta simboliza: el ideal nacional ruralista. Es decir, una vez más la censura admite una conducta reprochable porque hay una situación dramática de expiación: el pecador se arrepiente y con ello confirma la solidez del ideario franquista e insiste en su modelo de mujer. Acacias, en efecto, abandona a su esposo y a su hijo y pierde la honra (culpa). Cuando Juan, su marido, la encuentra tiempo después, la lleva a casa para hacer creer al abuelo que la honra familiar está limpia, pero le impide tocar a su hijo. Una vez que el abuelo muere, el marido la echa de casa y ella lleva una vida de miseria (castigo y expiación). Pero, finalmente, un día regresa a la aldea, pide perdón a Dios en la Iglesia y el marido la perdona también. Este ordena que se prepare una fiesta y hasta le lava los pies para decirle que está a su servicio (beatificación). Como la fiesta del patrón que abre la película, este cierre es un símbolo de humildad y pone fin al orgullo desmedido que tanto envenena la vida de los campesinos. «Por qué vamos a tener más orgullo que en la casa de Dios», dice Juan cuando todos le aconsejan que hay que echar a Acacias de la aldea. En realidad, Ecclesia considera que el filme va demasiado lejos:

Al perdón cristiano del marido ofendido nada se puede ni se debe oponer. Pero que al socaire de ese gesto generoso, de esa acogida cariñosa a la pecadora que vuelve, de las puertas de la iglesia abiertas y brindando perdón, no quede suficientemente afeada y estigmatizada la conducta inmoral de aquella mujer y su 
prostitución prolongada, y que todo termine entre repiques de campanas como si nada hubiese ocurrido nos parece sinceramente reprobable y totalmente inoportuno para nuestro público (28 de diciembre de 1942).

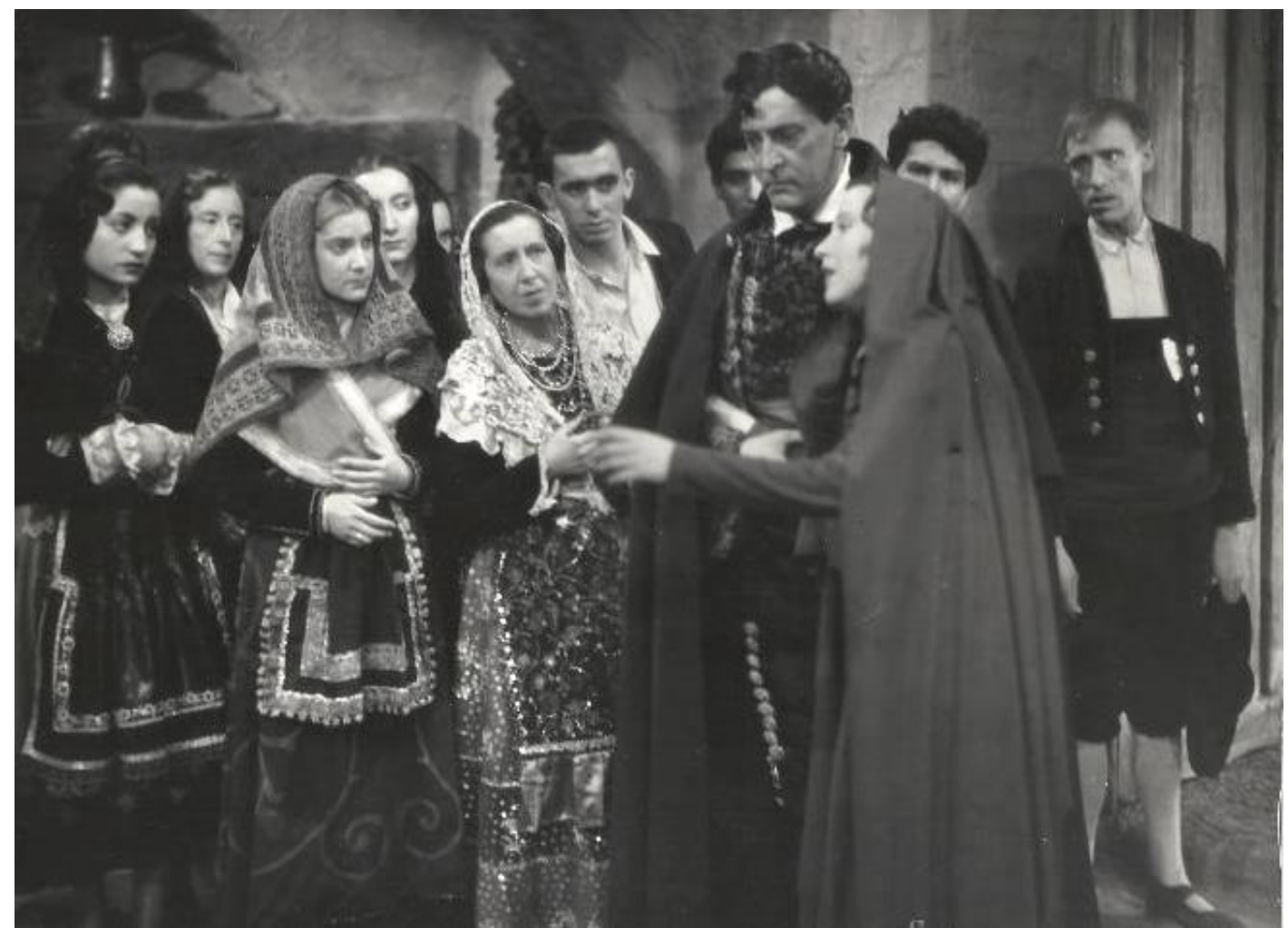

«Por qué vamos a tener más orgullo que en la casa de Dios», dice Juan cuando todos le aconsejan que hay que echar a Acacias de la aldea. Fuente: Filmoteca Española.

\subsection{La importancia de lo perdurable: Aquel viejo molino (1946)}

Finalmente, Aquel viejo molino es otra película que refleja muy bien el idilio rural, es decir, el amor por la tierra. De hecho, el argumentista y director de la película, Ignacio F. Iquino, afirma que pretendía rodar un filme de hondo sentido español que, sin recurrir a los tópicos, interesase al público autóctono y al extranjero. En España es declarada de Interés Nacional, aunque la censura pide que se adelante el fundido final para que el beso que cierra la película solo quede insinuado. De nuevo aparece el tema de la emigración. Lucas García (Adriano Rimoldi), el hijo de un molinero, emigra a la Argentina $y$, tras múltiples peripecias, vuelve rico muchos años después. Pero el molino de sus padres está abandonado. Su hija se casa con un muchacho en España y estos lo reconstruyen. Es decir, el molino simboliza la patria añorada. En su estreno en Madrid el público la aplaude por su línea sentimental y sus apuntes patrióticos. 


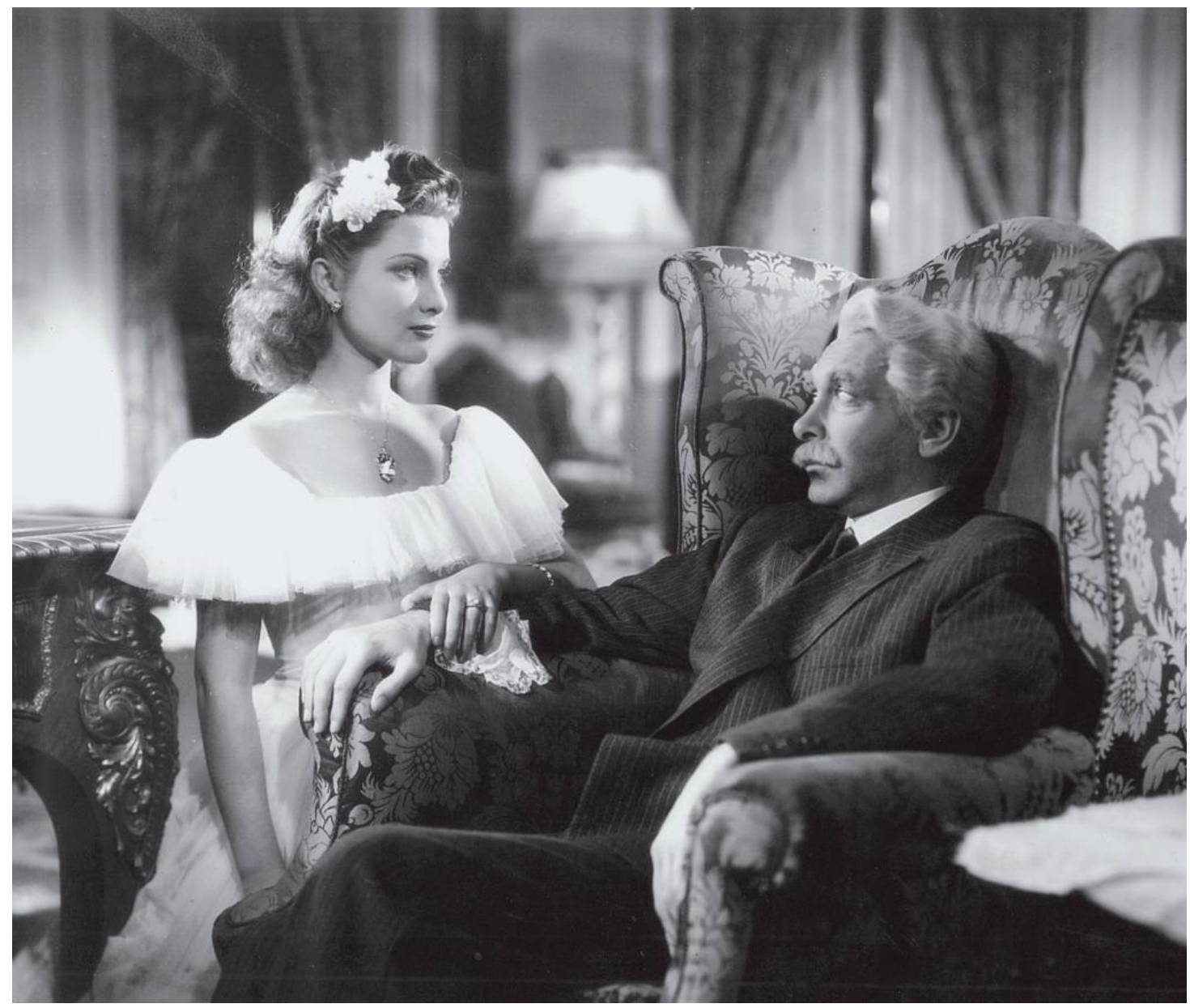

Fotograma de Aquel viejo molino: un rico emigrante regresa desde la Argentina para reconstruir el hogar familiar. Fuente: Filmoteca Española.

En Buenos Aires se estrena muy pronto, en mayo de 1947, y es el filme de este tipo de mayor éxito y calidad. El Heraldo dice que la película tiene interés y simpatía, buena realización y fotografía y un diálogo natural con expresiones graciosas. El crítico sitúa la acción en Andalucía. El rodaje se hace en Andalucía y La Mancha. Imparcial Film resalta la capacidad de la película para retratar la nostalgia por la tierra y los sentimientos humanos relacionados con los fuertes lazos que las personas establecen con los de su sangre y con la patria. Este canto a la emigración y a su apego por España explica que tuviese en la Argentina un gran éxito entre la colonia española, que no puede evitar las lágrimas en muchos momentos. Es más, en España la película se dio por perdida hasta que apareció una copia en, precisamente, Buenos Aires (Comas, 2002: 76).

\section{Conclusiones}

En definitiva, el drama rural permite expresar al franquismo su idea del regionalismo o nacionalismo regionalizado, arma ideológica contra el federalismo, el nacionalismo 
periférico y el separatismo. En las regiones, dice el régimen, reside lo más auténtico y lo más popular de una nación que, precisamente, se construye con la exaltación de lo local, lo provincial y lo regional. En sus discursos, Franco insiste una y otra vez en que para mantener la unidad de las tierras de España es preciso exaltar la rica multiplicidad de sus regiones, pues esa multiplicidad es la fuente de fortaleza de la unidad de la patria. Las películas mencionadas proyectan paisajes y costumbres de Aragón, Castilla, Extremadura o Andalucía.

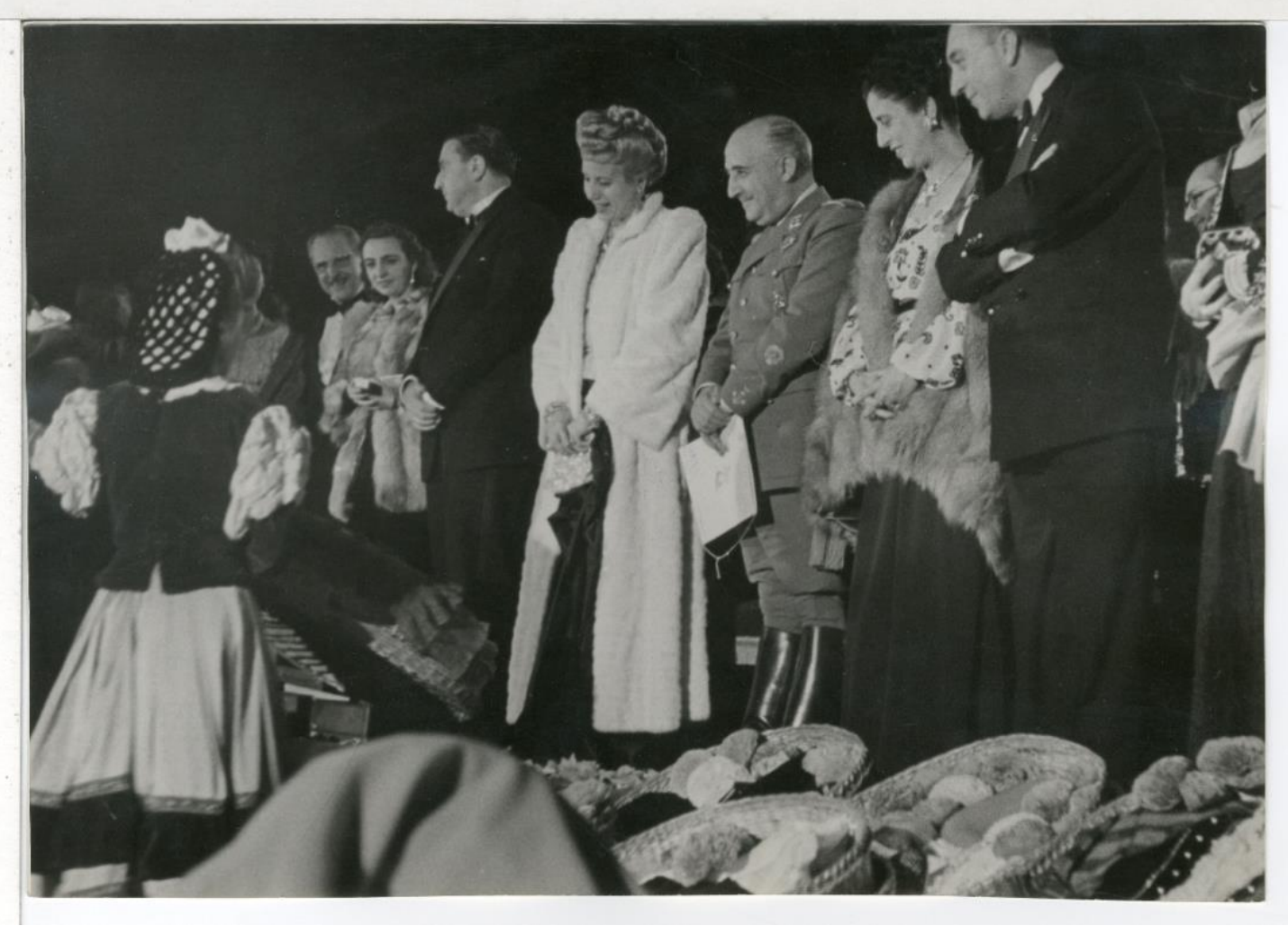

Eva Perón viaja a España en 1947. En uno de los actos preparados para ella, recibe ofrendas de las regiones. Están representadas por mujeres ataviadas con su traje regional mientras la primera dama argentina y las consortes visten pieles. Fuente: Archivo General de la Administración.

Al mismo tiempo, el drama rural plasma numerosos cantos y danzas regionales. Es un cine que también participa de la política falangista de "Coros y Danzas», es decir, de la recuperación de canciones y bailes populares. De hecho, en algún caso, un drama rural tiene tantos bailes y danzas como una película de las estrellas folclóricas: Imperio Argentina, Estrellita Castro, Juanita Reina... Incluso las tramas en ambos casos se centran en historias amorosas. La diferencia está en que el cine de las folklóricas cuenta cómo llegan al matrimonio la folclórica (el pueblo) y el señorito (el burgués). El drama rural expresa, a menudo, el conflicto entre el campesinado y el burgués, el hombre liberal de la ciudad. Además, lo andaluz parece requerir el tono cómico mientras el resto de las regiones del país se expresan dentro de lo dramático. Igualmente, las estrellas del drama rural rara vez cantan, por lo que se las identifica menos con las formas musicales. 
En cualquier caso, ambos géneros expresan el nacionalismo regionalizado del régimen. Demuestran que la aproximación al folklore y al tipismo popular son las formas que el cine franquista emplea para contar la verdadera España, pues la cultura local, provincial y regional, que es básicamente campesina, rural, representan la tradición popular y, por su pluralidad, constituye la riqueza etnográfica sobre la que hay que refundar y soldar el país. No se puede entender el franquismo sin su representación de la nación mediante canciones, bailes, peinados, vestidos $y$, en fin, costumbres regionales tradicionales. Naturalmente, a 10.000 kilómetros de España, este cine tiene un indudable valor sentimental para buena parte de la colonia de españoles emigrados.

\section{Referencias bibliográficas}

ALTHUSSER, L. (1989). «Ideología y aparatos ideológicos del estado», en La filosofía como arma de la revolución, México, Siglo XXI, pp. 102-151

BAJTIN, M., (1989). Teoría y estética de la novela, Madrid, Taurus.

BERGER, P. L. \& Luckmann, T. (1986). La construcción social de la realidad, Buenos Aires, Amorrortu.

BLANCO RODRÍGUEZ, J. A. (1998). «Sociedad y régimen en Castilla y León bajo el primer Franquismo», Historia Contemporánea, 17, pp. 359-385.

CCEBA (2011). Imágenes compartidas. Cine argentino - Cine español, Buenos Aires, CCEBA Apuntes.

COMAS, Á. (2002). IFI, Sociedad Anónima, empresa cinematográfica y escuela de cineastas y su artífice, Ignacio F. Iquino, Barcelona, UAB.

CUEVAS, A. (1950). Anuario Cinematográfico Hispanoamericano (1950-1951), Madrid, Sindicato Nacional del Espectáculo.

DE PEREDA, J. M. (1897). Discurso leído ante la Real Academia Española, Madrid, RAE.

DELGADO GÓMEZ-ESCALONILLA, L. (1988). Diplomacia franquista y política cultural hacia Iberoamérica, 1939-1953, Madrid, CSIC.

DIEZ PUERTAS, E. (2016). Cine transnacional y geopolítica hispanoamericana: el caso de España en sus relaciones con la Argentina (1931-1943), Madrid, Universidad Carlos III.

- (2017). El sueño de un cine hispano. España y sus relaciones cinematográficas con la Argentina (1931-1939), Madrid, Síntesis. 
FARÍAS, R. (2012). Apuntes sobre la presencia gallega en la Argentina. Todo es Historia, 6-27.

FIGALO, B. J. (1992). El protocolo Perón Franco: las relaciones hispano argentinas 19421952, Buenos Aires, Corregidor.

GARCÍA CARRIÓN, M. (2007). Sin cinematografía no hay nación. Drama e identidad nacional española en la obra de Florián Rey, Zaragoza, IFC.

GARCÍA SEBASTIANI, M. A. (2020). "Nacionalismos e identidad nacional entre los españoles en Argentina (1860-1975)», en Marcela Alejandra García Sebastiani, Xosé M. Núñez Seixas (coord.). Hacer patria lejos de casa: nacionalismo español, migración y exilio en Europa y América (1870-2010), Zaragoza, Universidad de Zaragoza.

GONZÁLEZ DE OLEAGA, M. (2001). El doble juego de la hispanidad: España y la Argentina durante la Segunda Guerra Mundial, Madrid, UNED.

GONZÁLEZ REQUENA, J. (1988). "Apuntes para una historia de lo rural en el cine español», en El campo en el cine español, Madrid, Filmoteca Española, pp. 13-27.

HIGBEE, W. \& HWEE LIM, S., (2010). "Concepts of transnational cinema: towards a critical transnationalism in film studies». Transnational Cinemas, 1 (1), pp. 7-21.

MANNING WHITE, D. \& AVERSON, R. (1974). El arma del celuloide, Buenos Aires, Marymar.

MARTÍ GÓMEZ, J. (1995). La España del estraperlo (1936-1952), Barcelona, Planeta.

MÉNDEZ-LEITE, F. (1965). Historia del cine españo, Madrid, Rialp.

ORTUÑO MARTÍNEZ, B. (2010). El exilio y la emigración española de posguerra en Buenos Aires, 1936-1956, Alicante, Universidad de Alicante.

- (2018). Hacia el hondo bajo fondo... Inmigrantes y exiliados en Buenos Aires tras la guerra civil española, Madrid, Biblioteca Nueva.

REIN, R. (1995). La salvación de una dictadura: alianza Franco-Perón 1946-1955, Madrid, CSIC.

SCHWARZSTEIN, D. (2001). Entre Franco y Perón. Memoria e identidad del exilio republicano español en Argentina, Barcelona, Crítica. 